\title{
Risk Factors and Outcomes of Preterm Birth among Northeastern Thai Teenage Mothers in Thailand
}

\author{
Suthida Intaraphet ${ }^{1}$, Supatra Kongpechr ${ }^{2}$, Sukanda Mahawerawat ${ }^{3}$, Ratchanee Potchana ${ }^{4}$
}

\begin{abstract}
Background and objectives: Teenage pregnancy itself is a risk factor for preterm birth in general. However, risk factors for preterm birth comparing teenage mothers who have preterm and no preterm birth are unaware. This study aimed to evaluate risk factors for preterm birth and outcomes of pregnancy among teenage mothers.

Materials and methods: A retrospective cohort study of all singleton teenage pregnancy cases giving birth from January 2014 to December 2015 at Khon Kaen Hospital, a tertiary hospital in Thailand, was conducted. Data on the characteristics of teenage mothers and outcomes of pregnancy were extracted from electronic files of medical records. Teenage mothers were classified into two groups according to gestational age at the time of delivery: term and preterm, to identify risk factors of preterm birth among teenage mothers. Multivariable logistic regression analysis was used to evaluate independent risk factors for preterm births among teenage mothers.

Results: During the study period, 1042 teenage mothers were identified. The preterm birth rate among teenage mothers was $16.8 \%$. BMI before pregnancy $<18.5 \mathrm{~kg} / \mathrm{m}^{2}(\mathrm{OR}, 1.89 ; 95 \% \mathrm{Cl}, 1.28-2.81)$, weight gain $<5 \mathrm{~kg}(\mathrm{OR}, 5.11 ; 95 \% \mathrm{Cl}, 2.96-8.81)$, prenatal care visit $<4$ times (OR, 5.16; 95\% $\mathrm{Cl}, 3.50-7.61)$, premature rupture of membranes $(\mathrm{OR}, 4.22$; $95 \% \mathrm{Cl}, 2.20-8.11)$, and previous preterm birth $(\mathrm{OR}, 46.56 ; 95 \% \mathrm{Cl}, 13.15-164.88)$ were found to be independent risk factors for preterm births among teenage mothers.

Conclusion: Previous preterm birth showed a very strong effect on current preterm birth. All risk factors for preterm birth should be considered to prevent preterm births among teenage mothers. Emphasizing the importance of prenatal care visits and proper nutrition for teenage pregnancy women would be beneficial.

Keywords: Adolescent, Preterm birth, Risk factors, Teenage pregnancy, Young mother.

Journal of South Asian Federation of Obstetrics and Gynaecology (2021): 10.5005/jp-journals-10006-1871
\end{abstract}

\section{INTRODUCTION}

Teenage pregnancy is defined as when girls, aged 10 to 19 years, become pregnant. ${ }^{1}$ Teenage girls constitute a high-risk group for adverse perinatal outcomes for both babies and teenage girls themselves. These include preterm birth, low birth weight, increased fetal mortality, ${ }^{2-5}$ pregnancy-induced hypertension (PIH), anemia, infection, increased emergency cesarean section, and postpartum blues. ${ }^{5,6}$ Moreover, the risk of preterm birth and fetal mortality remains high during the second birth involving teenage pregnancy. ${ }^{3}$

Preterm birth, a birth that occurs before the 37th week of pregnancy, ${ }^{7}$ is an important cause of morbidity and mortality among infants in both developing and developed countries. Globally, around 15 million preterm babies are born annually and approximately one million preterm babies die of complications from preterm birth. ${ }^{7,8}$ In 2014, across Asia-Pacific countries, 11 preterm babies out of 100 were born on average. While in Thailand, the preterm birth rate was $12 \% .{ }^{9}$ Complications of preterm birth comprised the second most common cause of death at $14.1 \%$ among infants aged lower than 5 years in $2010 .{ }^{8}$ Moreover, preterm babies have a greater risk of dying from other causes especially from infection. ${ }^{10}$ Most importantly, preterm birth may permanently affect some surviving babies involving cerebral palsy, learning impairments, or visual disorders, ${ }^{11}$ resulting in life-long disability among those babies.

The exact cause of preterm birth is unknown. However, related studies have found factors associated with preterm birth, including prior preterm birth, ${ }^{12}$ underlying diseases such as hypertension or diabetes mellitus, ${ }^{7,13}$ less BMI before pregnancy, ${ }^{14}$ less weight gain

\begin{abstract}
1,4 Department of Maternal, Child and Midwifery Nursing, Boromarajonani College of Nursing, Khon Kaen, Thailand

2,3 Department of Obstetrics and Gynecology, Khon Kaen Hospital, Khon Kaen, Thailand

Corresponding Author: Suthida Intaraphet, Department of Maternal, Child and Midwifery Nursing, Boromarajonani College of Nursing, Khon Kaen, Thailand, Phone: +66 863153596, e-mail: yrai250@hotmail.com

How to cite this article: Intaraphet S, Kongpechr S, Mahawerawat S, et al. Risk Factors and Outcomes of Preterm Birth among Northeastern Thai Teenage Mothers in Thailand. J South Asian Feder Obst Gynae 2021;13(2):111-116.
\end{abstract}

Source of support: Nil

Conflict of interest: None

during pregnancy, ${ }^{15}$ and no antenatal care (ANC). ${ }^{16}$ Nevertheless, no risk factors for preterm birth were observed among many preterm babies. $^{17}$

Teenage pregnancy is known to be a risk factor for preterm birth in general. ${ }^{17,18}$ Several studies have investigated risk factors for preterm birth among teenage mothers, compared with optimum reproductive age mothers. ${ }^{3,5,19}$ However, we are unaware of studies concerning risk factors for preterm birth among teenage mothers, comparing risk factors between teenage mothers having preterm and no preterm birth. In this study, we performed a retrospective review to evaluate risk factors for preterm birth and outcomes of pregnancy among teenage mothers in a tertiary hospital in Northeastern Thailand. 


\section{Materials and Methods}

This retrospective cohort study was conducted after obtaining approval from the Ethics Review Board of Khon Kaen Hospital (record number KE59091), a tertiary hospital located in the Northeastern region of Thailand. As this study did not involve any contact with participants or any interventions, signed consent forms were unnecessary. All singleton teenage mothers giving birth at Khon Kaen Hospital, Thailand, from January 2014 to December 2015 were reviewed. Preterm birth was defined as a birth occurring prior to completion of 37 weeks of gestation. ${ }^{7}$ The main outcome was the detection of preterm birth. The variables included in the analyses were BMI before pregnancy, weight gain during pregnancy, night sleeping, prenatal care visit, previous preterm birth, previous abortion, premature rupture of membranes (PROMs), and anemia. For the duration of prenatal visits, we used the American College of Obstetrics and Gynecology guidelines for the schedule of prenatal care visits: every 4 weeks from the first prenatal visit until 28 weeks, every 2 weeks from 28 weeks to 36 weeks, and every week afterward. ${ }^{20}$ Based on our data, we dichotomized weight gain as $<5 \mathrm{~kg}$ and $\geq 5 \mathrm{~kg}$ for the cutoff point. According to the four-visit ANC model outlined in WHO clinical guidelines ${ }^{21}$ that we used at the time of study period, prenatal care visit was divided as $<4$ times and $\geq 4$ times. Teenage mothers were classified into two groups according to gestational age at the time of delivery; term and preterm, to identify risk factors of preterm birth among teenage mothers. Data and information on characteristics of those teenage mothers and outcomes of pregnancy were extracted from electronic files of medical records.

\section{Statistical Analysis}

The data were analyzed using STATA, version 11 (StataCorp LP, College Station, TX, USA) software. Baseline characteristics of teenage mothers and outcomes of pregnancy were presented using descriptive statistics. The association of gestational-age group and characteristics of teenage mothers and outcomes of pregnancy were assessed using the exact probability test. We evaluated risk factors of preterm birth among teenage mothers using logistic regression analysis. Risk factors with statistical significance in univariable analyses were further assessed using multivariable analyses to identify independent risk factors for preterm birth. All tests were two-tailed, and $P$ values of less than 0.05 were considered statistically significant.

\section{Results}

A total of 9294 women gave birth at the delivery room of Khon Kaen Hospital between January 2014 and December 2015. Of these, 1042 singleton teenage mothers were identified. The preterm birth rate among those teenage mothers was $16.8 \%$. The teenage mothers' age ranged from 13 to 19 years, and the mean age was $17.5( \pm 1.4)$ years. Characteristics of the entire group by gestational age at delivery, divided in term and preterm groups, are shown in Table 1. The proportion of low BMI before pregnancy, low weight gain, few prenatal care visits, previous preterm birth, and PROM were significantly higher in the preterm group. The mean (SD) of gestational age at delivery in the preterm group was $33.68( \pm 2.93)$ weeks (Table 1).

In the preterm group, around $68 \%$ of teenage mothers gave birth with low birth weights of less than $2500 \mathrm{gm}$ compared with $7.16 \%$ in the term group (Table 2). A significantly higher proportion of fetal anomalies, such as gastroschisis, anencephaly, hydrocephaly, and cardiac anomaly, were found in the preterm group compared with the term group. There was no incident of stillbirth in the term group while a higher rate of $1.7 \%$ was observed in the preterm group. The proportions were comparable between the two groups regarding maternal complications and underlying diseases, such as PIH, gestational diabetes mellitus, thyroid disease, syphilis, thalassemia, HIV infection, heart disease, and condyloma acuminata. Other outcomes of teenage pregnancies, according to gestational age group, are depicted in Table 2.

Table 3 showed univariable analysis of risk factors for preterm birth among teenage mothers compared with those who gave birth at term. Our findings revealed that BMI before pregnancy $<18.5 \mathrm{~kg} / \mathrm{m}^{2}$, weight gain $<5 \mathrm{~kg}$, prenatal care visits $<4$ times, previous preterm birth, and PROM were found to be risk factors of preterm birth. Teenage mothers with anemia seemed to show a higher risk of preterm birth, but without significance (OR, 1.37; 95\%Cl, 0.92-2.04) (Table 3).

Using multivariable analysis, we further included all risk factors with statistical significance in univariable analyses of the model. The findings showed that all significant risk factors in univariable analyses, including BMI before pregnancy $<18.5 \mathrm{~kg} / \mathrm{m}^{2}$, weight gain $<5 \mathrm{~kg}$, prenatal care visit $<4$ times, previous preterm birth, and PROM, were also found to be independent risk factors for preterm birth among our teenage mothers, with a very high odd ratio of previous preterm birth (OR, 46.56; 95\% Cl, 13.15-164.88) (Table 4).

\section{Discussion}

Teenage pregnancy is considered a public health problem that should be carefully considered in a comprehensive manner due to its long-term consequences. Our findings revealed unfavorable outcomes and complications among teenage mothers even regarding term pregnancy. BMI before pregnancy $<18.5 \mathrm{~kg} / \mathrm{m}^{2}$, weight gain $<5 \mathrm{~kg}$, prenatal care visit $<4$ times, previous preterm birth, and PROM were found to be independent risk factors for preterm birth.

Our study also showed that the preterm birth rate among teenage mothers in Khon Kaen province was rather high (16.8\%), which was higher than the overall preterm birth rate of our country $(12 \%){ }^{9}$ In line with the preterm birth rate reported in a systematic review of the worldwide incidence of preterm births, the highest rates of preterm births were $11.9 \%$ and $10.6 \%$ of all births, found in Africa and North America, respectively. ${ }^{22}$ In contrast, a retrospective study of over 10 years, selecting a random sample of women aged under 20 years in Washington State, revealed a relatively low rate of preterm birth among teenage mothers at only $7 \%,{ }^{23}$ while the overall preterm birth rate in the US was about $12-13 \% .{ }^{24}$ Teenage mothers had unpromising outcomes and complications in our study. Maternal complications and fetal anomalies were found in both term and preterm groups, though at a higher number and greater severity in the preterm group. Our results were consistent with related studies of adverse perinatal outcomes for both babies and teenage mothers, showing that teenage mothers had increased risks for preterm birth, low birth weight, and neonatal morbidity and mortality. ${ }^{2-5,19}$ At the same time, teenage mothers themselves also experienced a higher risk of $\mathrm{PIH}$, emergency cesarean section, infection, anemia, and postpartum blues. . $^{5,6}$

Our findings revealed many independent risk factors for preterm birth among teenage mothers. Previous preterm birth showed a very strong effect on current preterm birth. Teenage 
Table 1: Baseline characteristics of teenage mothers according to gestational-age group at delivery

\begin{tabular}{|c|c|c|c|c|c|}
\hline \multirow[b]{2}{*}{ Characteristics } & \multicolumn{2}{|c|}{ Preterm group $(n=176)$} & \multicolumn{2}{|c|}{ Term group $(n=866)$} & \multirow[b]{2}{*}{$P$-value } \\
\hline & $n$ & (\%) & $n$ & (\%) & \\
\hline \multicolumn{6}{|l|}{ Age (years) } \\
\hline Mean (SD) & $17.27(1.50)$ & - & $17.54(2.12)$ & - & 0.106 \\
\hline \multicolumn{6}{|l|}{ Education } \\
\hline Primary school & 40 & 22.73 & 176 & 20.32 & 0.628 \\
\hline Junior high school & 104 & 59.09 & 545 & 62.93 & \\
\hline Senior high school & 26 & 14.77 & 125 & 14.43 & \\
\hline Higher education & 6 & 3.41 & 20 & 2.32 & \\
\hline \multicolumn{6}{|l|}{ Occupation } \\
\hline Out of work/housewife & 147 & 83.52 & 730 & 84.30 & 0.566 \\
\hline Employee & 22 & 12.50 & 92 & 10.62 & \\
\hline Merchant & 4 & 2.27 & 34 & 3.93 & \\
\hline Farmer & 3 & 1.71 & 10 & 1.15 & \\
\hline \multicolumn{6}{|l|}{ Gravida } \\
\hline G1 & 147 & 83.52 & 686 & 79.21 & 0.216 \\
\hline G2 and greater & 29 & 16.48 & 180 & 20.79 & \\
\hline \multicolumn{6}{|c|}{ BMI before pregnancy $\left(\mathrm{kg} / \mathrm{m}^{2}\right)$} \\
\hline$<18.5$ & 80 & 45.46 & 259 & 29.90 & 0.003 \\
\hline $18.5-24.9$ & 86 & 48.86 & 506 & 58.43 & \\
\hline $25-29.9$ & 5 & 2.84 & 69 & 7.97 & \\
\hline$\geq 30$ & 5 & 2.84 & 32 & 3.70 & \\
\hline Mean (SD) & $19.82(4.14)$ & - & $20.77(3.90)$ & - & \\
\hline \multicolumn{6}{|l|}{ Weight gain $(\mathrm{kg})$} \\
\hline$<5$ & 42 & 23.86 & 38 & 4.39 & $<0.001$ \\
\hline$\geq 5$ & 134 & 76.14 & 828 & 95.61 & \\
\hline \multicolumn{6}{|l|}{ Night sleeping (hr) } \\
\hline$<8$ & 26 & 14.77 & 134 & 15.47 & 0.909 \\
\hline$\geq 8$ & 150 & 85.23 & 732 & 84.53 & \\
\hline Mean (SD) & $8.52(1.33)$ & - & $8.49(1.36)$ & - & \\
\hline \multicolumn{6}{|l|}{ Prenatal care visit (time) } \\
\hline$<4$ & 112 & 63.64 & 197 & 22.75 & $<0.001$ \\
\hline$\geq 4$ & 64 & 36.36 & 669 & 77.25 & \\
\hline \multicolumn{6}{|l|}{ Previous preterm birth } \\
\hline Yes & 28 & 15.91 & 3 & 0.35 & $<0.001$ \\
\hline No & 148 & 84.09 & 863 & 99.65 & \\
\hline \multicolumn{6}{|l|}{ Previous abortion } \\
\hline Yes & 12 & 6.82 & 78 & 9.01 & 0.461 \\
\hline No & 164 & 93.18 & 788 & 90.99 & \\
\hline \multicolumn{6}{|l|}{ PROM } \\
\hline Yes & 26 & 14.77 & 33 & 3.81 & $<0.001$ \\
\hline No & 150 & 85.23 & 833 & 96.19 & \\
\hline \multicolumn{6}{|l|}{ Anemia } \\
\hline Yes & 38 & 21.59 & 145 & 16.74 & 0.129 \\
\hline No & 138 & 78.41 & 721 & 83.26 & \\
\hline \multicolumn{6}{|l|}{ GA at delivery (week) } \\
\hline Mean (SD) & $33.68(2.93)$ & - & $38.75(1.12)$ & - & $<0.001$ \\
\hline
\end{tabular}

$\mathrm{BMI}$, body mass index; PROM, premature rupture of membrane; GA, gestational age

mothers having a previous preterm birth had around 47 times (OR, $46.56 ; 95 \% \mathrm{Cl}, 13.15-164.88$ ) higher risk of giving preterm birth for the subsequent pregnancy, though the value was rather imprecise. Consistently, a related study found that women who had PROM and who had preterm birth without PROM were 6.34 and 21.28 times more likely to have had preterm birth in the preceding pregnancy, respectively. However, this study included women aged 15 to 45 years in the study. ${ }^{25}$ Similarly, a systematic review and meta-analysis of risk of recurrent spontaneous preterm birth (sPTB) demonstrated that a previous sPTB constituted a significant risk factor for recurrent preterm birth in subsequent pregnancies with the absolute risk of $30 \%(95 \% \mathrm{Cl}, 27-34 \%) .{ }^{26}$ Preterm PROM was also found to be a risk factor for SPTB with the absolute risk of $7 \%(95 \% \mathrm{Cl}, 6-9 \%)$ in this study. This result was similar to our 
Table 2: Crude outcomes of teenage mothers

\begin{tabular}{|c|c|c|c|c|c|}
\hline \multirow[b]{2}{*}{ Outcomes } & \multicolumn{2}{|c|}{ Preterm group $(n=176)$} & \multicolumn{2}{|c|}{ Term group $(n=866)$} & \multirow[b]{2}{*}{ P-value } \\
\hline & $n$ & (\%) & $n$ & (\%) & \\
\hline \multicolumn{6}{|l|}{ Types of delivery } \\
\hline Vaginal delivery & 135 & 77.59 & 547 & 63.16 & $<0.001$ \\
\hline Forceps extraction & 3 & 1.72 & 7 & 0.81 & \\
\hline Vacuum extraction & 1 & 0.57 & 46 & 5.31 & \\
\hline Cesarean section & 35 & 20.11 & 266 & 30.72 & \\
\hline \multicolumn{6}{|c|}{ Maternal complication or underlying diseases } \\
\hline Yes & 32 & 18.18 & 135 & 15.59 & 0.430 \\
\hline No & 144 & 81.82 & 731 & 84.41 & \\
\hline \multicolumn{6}{|c|}{ Emergency cesarean section } \\
\hline Yes & 32 & 91.43 & 209 & 78.57 & 0.112 \\
\hline No & 3 & 8.57 & 57 & 21.43 & \\
\hline \multicolumn{6}{|l|}{ Birth weight (gm) } \\
\hline$<2500$ & 119 & 67.61 & 62 & 7.16 & $<0.001$ \\
\hline $2500-3500$ & 56 & 31.82 & 709 & 81.87 & \\
\hline$>3500$ & 1 & 0.57 & 95 & 10.97 & \\
\hline Mean (SD) & 2162.09 & & 3057.23 & & \\
\hline & $(602.36)$ & & (394.84) & & \\
\hline \multicolumn{6}{|l|}{ APGAR score at $1 \mathrm{~min}$} \\
\hline$<7$ & 32 & 18.18 & 38 & 4.39 & $<0.001$ \\
\hline$\geq 7$ & 144 & 81.82 & 828 & 95.61 & \\
\hline \multicolumn{6}{|l|}{ APGAR score at $5 \mathrm{~min}$} \\
\hline$<7$ & 19 & 10.80 & 10 & 1.15 & $<0.001$ \\
\hline$\geq 7$ & 157 & 89.20 & 856 & 98.85 & \\
\hline \multicolumn{6}{|l|}{ Fetal anomaly } \\
\hline Yes & 4 & 2.27 & 5 & 0.58 & 0.049 \\
\hline No & 172 & 97.73 & 861 & 99.42 & \\
\hline \multicolumn{6}{|l|}{ Stillbirth } \\
\hline Yes & 3 & 1.70 & 0 & 0.00 & 0.005 \\
\hline No & 173 & 98.30 & 866 & 100 & \\
\hline
\end{tabular}

findings that revealed PROM as an independent risk factor of preterm birth (OR, 4.22; $95 \% \mathrm{Cl}, 2.20-8.11)$. The reason underlying the likelihood of mortality according to preterm is due both to immaturity and pathologic conditions, because immaturity and pathology are not mutually exclusive. Immaturity can worsen the effects of fetal pathology and pathology itself may affect fetal maturation. ${ }^{27}$

Several previous studies have revealed an association between maternal body weight and preterm birth. ${ }^{14,15}$ Likewise, we found a positive association between both BMI before pregnancy $<18.5 \mathrm{~kg} / \mathrm{m}^{2}$ and weight gain $<5 \mathrm{~kg}$ and the increased risk of preterm birth among teenage mothers with OR of 1.89 (95\% Cl, 1.28-2.81) and $5.11(95 \% \mathrm{Cl}, 2.96-8.81)$, respectively. In a study among African-American women, including women aged 21 to 44 years old, the findings showed that, though few women were in the category of low BMI, BMI $<18 \mathrm{~kg} / \mathrm{m}^{2}$ before pregnancy was an independent risk factor for SPTB. Women with $\mathrm{BMI}<18 \mathrm{~kg} / \mathrm{m}^{2}$ had 2.72 times $(95 \% \mathrm{Cl}, 1.43-5.17)$ greater risk of sPTB compared with those with BMI 20 to $24 \mathrm{~kg} / \mathrm{m}^{2}$. Teenage mothers with low gestational weight gain $<0.5 \mathrm{lb} /$ week in the second and third trimesters were found to have increased risk for SPTB with OR of $1.51(95 \% \mathrm{Cl}, 1.17-1.97)$ compared with those mothers gaining 0.5-1.4 lb/week. Moreover, those gaining $\geq 1.5 \mathrm{lb} /$ week were also at increased risk for SPTB (OR 1.42, 95\% Cl, 1.13-1.78) in this study. ${ }^{14}$ Similarly, another study demonstrated that women with low gestational weight gain were at increased risk for preterm birth, especially among women who were underweight (OR 6.7, 95\% Cl 1.1-40.6). ${ }^{15}$ These findings as well as our results emphasized the importance of proper nutrition for pregnant women.

Not surprisingly, few prenatal care visits were also important independent risk factors for preterm birth in our study. Teenage mothers who had prenatal care visits $<4$ times had 5.16 times $(95 \%$ $\mathrm{Cl}, 3.50-7.61)$ higher risk of preterm birth compared with those who had prenatal care visit $\geq 4$ times. Similarly, a recent study in southern Thailand which included 2459 women who delivered at the study settings showed that women who had ANC visit $<4$ times had 2.83 times $(95 \% \mathrm{Cl}, 1.67-4.80)$ greater risk of preterm birth compared with women who had ANC visit of 4-10 times in multivariable analysis. ${ }^{28} \mathrm{~A}$ retrospective study on prenatal care and risk of preterm birth among teenage pregnancy over a period of 10 years also revealed that teenage mothers without prenatal care had around seven times higher risk of preterm birth compared with those who attended $75-100 \%$ of recommended prenatal visits. The risk decreased linearly as prenatal care increased. Teenage mothers with less than $25 \%, 25$ to $49 \%$, or 50 to $74 \%$ of expected prenatal visits were at greater risk of preterm birth with OR of $2.5,1.5$, and 1.3 , respectively. ${ }^{23}$ Similarly, another integrative literature review indicated that women without or having insufficient prenatal care were at increased risk of preterm 
Table 3: Univariable analysis of risk factors for preterm birth in teenage mothers compared with those who gave birth at term gestational age

\begin{tabular}{|c|c|c|}
\hline Risk factors & Unadjusted odds ratio $(95 \% \mathrm{Cl})$ & $p$-value \\
\hline $\begin{array}{l}\text { BMI before pregnancy } \\
\begin{array}{l}\left(\mathrm{kg} / \mathrm{m}^{2}\right) \\
<18.5 \\
\geq 18.5\end{array}\end{array}$ & $\begin{array}{l}1.95(1.40-2.7) \\
\text { Reference }\end{array}$ & $<0.001$ \\
\hline $\begin{array}{l}\text { Weight gain }(\mathrm{kg}) \\
\quad<5 \\
\geq 5\end{array}$ & $\begin{array}{l}6.83(4.25-10.98) \\
\text { Reference }\end{array}$ & $<0.001$ \\
\hline $\begin{array}{l}\text { Night sleeping (hr) } \\
\quad<8 \\
\geq 8\end{array}$ & $\begin{array}{l}0.95(0.60-1.49) \\
\text { Reference }\end{array}$ & 0.814 \\
\hline $\begin{array}{l}\text { Prenatal care visit (time) } \\
\quad<4 \\
\geq 4\end{array}$ & $\begin{array}{l}5.94(4.21-8.39) \\
\text { Reference }\end{array}$ & $<0.001$ \\
\hline $\begin{array}{l}\text { Previous preterm birth } \\
\text { Yes } \\
\text { No }\end{array}$ & $\begin{array}{l}54.42(16.34-181.30) \\
\text { Reference }\end{array}$ & $<0.001$ \\
\hline $\begin{array}{l}\text { Previous abortion } \\
\text { Yes } \\
\text { No }\end{array}$ & $\begin{array}{l}0.74(0.39-1.39) \\
\text { Reference }\end{array}$ & 0.348 \\
\hline $\begin{array}{l}\text { PROM } \\
\text { Yes } \\
\text { No }\end{array}$ & $\begin{array}{l}4.38(2.54-7.53) \\
\text { Reference }\end{array}$ & $<0.001$ \\
\hline $\begin{array}{l}\text { Anemia } \\
\text { Yes } \\
\text { No }\end{array}$ & $\begin{array}{l}1.37(0.92-2.04) \\
\text { Reference }\end{array}$ & 0.125 \\
\hline
\end{tabular}

BMI, body mass index; PROM, premature rupture of membrane.

Table 4: Multivariable analysis of risk factors for preterm birth in teenage mothers compared with those who gave birth at term gestational age

\begin{tabular}{lcc}
\hline Risk factors & $\begin{array}{l}\text { Adjusted odds ratio } \\
\text { (95\% Cl) }\end{array}$ & p-value \\
\hline BMI before pregnancy $<18.5 \mathrm{~kg} / \mathrm{m}^{2}$ & $1.89(1.28-2.81)$ & 0.001 \\
Weight gain $<5 \mathrm{~kg}$ & $5.11(2.96-8.81)$ & $<0.001$ \\
Prenatal care visit $<4$ times & $5.16(3.50-7.61)$ & $<0.001$ \\
Previous preterm birth & $46.56(13.15-164.88)$ & $<0.001$ \\
PROM & $4.22(2.20-8.11)$ & $<0.001$ \\
\hline
\end{tabular}

$\mathrm{BMI}$, body mass index; PROM, premature rupture of membrane

birth. ${ }^{17}$ As many pregnant teenagers seem not to realize the importance of prenatal care, actively emphasizing the reasons to comply with the schedule of prenatal visits would be greatly important.

To our knowledge, this is the first study comparing risk factors between teenage mothers having preterm and no preterm birth, which strengthened the study. We also recognize some limitations in our study regarding the retrospective design using an established database. The medical records were sometimes incomplete, resulting in lifestyle and environmental factors, such as smoking, drinking alcohol, using illegal drugs, and domestic violence, that could not be evaluated in this study. Moreover, some information according to fetal outcomes after birth such as neonatal death could not be accessed by electronic files.

\section{Conclusion}

Previous preterm birth, BMI before pregnancy of less than $18.5 \mathrm{~kg} / \mathrm{m}^{2}$, weight gain $<5 \mathrm{~kg}$, prenatal care visits $<4$ times, and PROM were independent risk factors for preterm birth among teenage mothers in our study. Teenage pregnancy should be concerned with the high risk of adverse birth outcomes. All risk factors of preterm birth in our findings should be considered to reduce or prevent preterm birth among teenage mothers. Emphasizing the importance of prenatal care visits and proper nutrition for teenage pregnant women would be beneficial.

\section{Acknowledgment}

This study was funded by Boromarajonani College of Nursing Khon Kaen, Thailand.

\section{References}

1. WHO. Adolescent pregnancy: issues in adolescent health and development. Available at: http://apps.who.int/iris/ bitstream/10665/42903/1/9241591455_eng.pdf (accessed 25 March 2015).

2. Chen XK, Wen SW, Fleming N, et al. Teenage pregnancy and adverse birth outcomes: a large population based retrospective cohort study. Int J Epidemiol 2007;36:368. DOI: 10.1093/ije/dyl284.

3. Smith GC, Pell JP. Teenage pregnancy and risk of adverse perinatal outcomes associated with first and second births: population based retrospective cohort study. BMJ 2001;323:476. DOI: 10.1136/ bmj.323.7311.476.

4. Kumar A, Singh T, Basu S, et al. Outcome of teenage pregnancy. Indian J Pediatr 2007;74:927. DOI: 10.1007/s12098-007-0171-2.

5. Thaithae S, Thato R. Obstetric and perinatal outcomes of teenage pregnancies in Thailand. J Pediatr Adolesc Gynecol 2011;24:342. DOI: 10.1016/j.jpag.2011.02.009.

6. Jeha D, Usta I, Ghulmiyyah L, et al. A review of the risks and consequences of adolescent pregnancy. J Neonatal Perinatal Med. 2015. DOI: $10.3233 / \mathrm{NPM}-15814038$.

7. WHO. Preterm birth: fact sheet. 2018 [updated 2018; cited 2018 Sep 5]. Available at: http://www.who.int/mediacentre/factsheets/fs363/en/

8. Liu L, Johnson HL, Cousens S, et al. Global, regional, and national causes of child mortality: an updated systematic analysis for 2010 with time trends since 2000. Lancet 2012;379:2151. DOI: 10.1016/ S0140-6736(12)60560-1.

9. OECD/WHO. Health at a glance: Asia/Pacific 2018: measuring progress towards universal health coverage. Paris: OECD Publishing, 2018. DOI: 10.1787/health_glance_ap-2018-en.

10. Blencowe $\mathrm{H}$, Cousens $\mathrm{S}$, Chou $\mathrm{D}$, et al. Born too soon: the global epidemiology of 15 million preterm births. Reprod Health 2013;10:S2. DOI: 10.1186/1742-4755-10-S1-S2.

11. Rogers LK, Velten M. Maternal inflammation, growth retardation, and preterm birth: insights into adult cardiovascular disease. Life Sci 2011;89:417. DOI: 10.1016/j.lfs.2011.07.017.

12. Hamad KA, Abed Y, Hamad BA. Risk factors associated with preterm birth in the Gaza Strip: hospital-based case-control study. East Mediterr Health J 2007;13:1132. DOI: 10.26719/2007.13.5.1132.

13. Edstedt Bonamy AK, Bengtsson J, Nagy Z, et al. Preterm birth and maternal smoking in pregnancy are strong risk factors for aortic narrowing in adolescence. Acta Paediatr 2008;97:1080. DOI: 10.1111/j.1651-2227.2008.00890.x.

14. Wise LA, Palmer JR, Heffner LJ, et al. Prepregnancy body size, gestational weight gain, and risk of preterm birth in AfricanAmerican women. Epidemiology 2010;21:243. DOI: 10.1097/ EDE.0b013e3181cb61a9.

15. Schieve LA, Cogswell ME, Scanlon KS, et al. Prepregnancy body mass index and pregnancy weight gain: associations with preterm delivery. The NMIHS Collaborative Study Group. Obstet Gynecol 2000;96:194. DOI: 10.1016/s0029-7844(00)00883-8. 
16. Vintzileos AM, Ananth CV, Smulian JC, et al. The impact of prenatal care in the United States on preterm births in the presence and absence of antenatal high-risk conditions. Am J Obstet Gynecol 2002;187:1254. DOI: 10.1067/mob.2002.127140.

17. Thomazini IFS, Wysocki $A D$, da Cunha MCB, et al. Risk factors related to premature labor in pregnant adolescents: an integrative literature review. Enfermaria Glob 2016;15:440. DOI:10.6018/ eglobal.15.4.236961.

18. Partington SN, Steber DL, Blair KA, et al. Second births to teenage mothers: risk factors for low birth weight and preterm birth. Perspect Sex Reprod Health 2009;45:101. DOI: 10.1363/4110109.

19. Khashan AS, Baker PN, Kenny LC. Preterm birth and reduced birthweight in first and second teenage pregnancies: a registerbased cohort study. BMC Pregnancy Childbirth 2010;10:36. DOI: 10.1186/1471-2393-10-36.

20. American Academy of Pediatrics. Antepartum care. In: Guidelines for perinatal care, 6th ed. Washington DC: American College of Obstetricians and Gynecologists, 2007, pp. 83-137.

21. WHO. WHO antenatal care randomized trial: manual for the implementation of the new model. Geneva: World Health Organization; 2002. Available at: http://www.who.int/reproductivehealth/ publications/maternal_perinatal_health/RHR_01_30/en/ (accessed 6 October 2015).
22. Beck S, Wojdyl D, Say L, et al. The worldwide incidence of preterm birth: a systematic review of maternal mortality and morbidity. Bull World Health Organ 2010;88:31. DOI: 10.2471/BLT.08.062554.

23. Debiec KE, Paul KJ, Mitchell CM, et al. Inadequate prenatal care and risk of preterm delivery among adolescents: a retrospective study over 10 years. Am J Obstet Gynecol. 2010. DOI: 10.1016/j. ajog.2010.03.001.

24. Goldenberg RL, Culhane JF, lams JD, et al. Epidemiology and causes of preterm birth. Lancet 2008;371:75. DOI: 10.1016/S01406736(08)60074-4.

25. Ekwo EE, Gosselink CA, Moawad A. Unfavorable outcome in penultimate pregnancy and premature rupture of membranes in successive pregnancy. Obstet Gynecol 1992;80:166. PMID:1635725.

26. Phillips C, Velji Z, Hanly C, et al. Risk of recurrent spontaneous preterm birth: a systematic review and meta analysis. BMJ Open. 2017. DOI: 10.1136/ bmjopen-2016-015402.

27. Basso $\mathrm{O}$, Wilcox A. Mortality risk among preterm babies: immaturity versus underlying pathology. Epidemiology 2010;21:521. DOI: 10.1097/EDE.0b013e3181debe5e.

28. Liabsuetrakul T, Defever K, Lawantrakul J, et al. Evaluation of an epidemiological surveillance system for preterm birth and low birth weight in Southern Thailand. J Health Sci Med Res 2019;37:5. DOI: 10.31584/jhsmr.201933. 